\title{
Improved Pancreaticoduodenectomy Outcomes after Starting a Specialized Community Hospital Pancreatic Surgery Program
}

\author{
George Younan ${ }^{1,2, *}$, Maged Andrews ${ }^{3}$, Umadevi Rangarajan ${ }^{3}$, Danielle Eganhouse ${ }^{2}$, Robert F. Ahmed ${ }^{1,2}$, \\ Timothy R. Shaver ${ }^{1,2}$
}

${ }^{I}$ Department of Surgery, Inova Fair Oaks Hospital, Fairfax, VA.

${ }^{2}$ Division of Hepato, Pancreato, Biliary Surgery, Virginia Surgery Associates, Fairfax, VA.

${ }^{3}$ Department of Anesthesiology, North American Partners in Anesthesia, Inova Fair Oaks Hospital, Fairfax, VA.

\begin{abstract}
Background: Recent trends in centralization of pancreatic surgery happened as a response to improved outcomes in tertiary care institutions. The volume-outcome relationship is true for high volume hospitals and surgeons. Obstacles to patient travelling to high volume institutions and widespread quality care in community hospitals led to establishing a quality specialized pancreatic surgery program in the community.

Methods: Two pancreatic surgery specialists relocated their program from a tertiary care center to a community hospital. Results of the first sixty-two pancreaticoduodenectomy and total pancreatectomy procedures were studied.

Results: One hundred and seventeen pancreatic surgery cases were analyzed, sixty-two pancreaticoduodenectomy and total pancreatectomy cases were included. Patient demographics were not different in regard to the median age (67 vs. 62 years), gender ( 65 vs. $62 \%$ males), median BMI ( 26.2 vs. $\left.26 \mathrm{~kg} / \mathrm{m}^{2}\right)$, or American Society of Anesthesiologists class, in between the two hospitals. There was a significant decrease in the operative time ( 350 vs. 281 minutes, $p=0.0001$ ), estimated blood loss ( 409 vs. 156 milliliters, $\mathrm{p}=0.003)$, and length of hospital stay ( 7.2 vs. 5.2 days, $\mathrm{p}=0.0001$ ). Most patients were operated on for a diagnosis of malignancy (74.2\%), and the R0 resection rate was better at the community hospital reaching $95.2 \%$. Transfusions, delayed gastric emptying and leaks tended to be better at the community hospital but did not reach statistical significance.
\end{abstract}

Conclusion: With dedicated institutional support and careful program design, complex procedures such as PD can be successfully relocated to the community where superior results can be achieved.

\section{KEYWORDS}

Pancreaticoduodenectomy, Whipple, Enhanced recovery, Community hospital.

Correspondins Author Information

George Younan, MD,

Virginia Surgery Associates, 3620 Joseph Siewick Drive \#406, Fairfax, VA 22033, Tel: 703-359-8640; Fax: 703-591-6105.

Received: July 19, 2020; Accepted: August 11, 2020; Published: August 15, 2020

Copyright: (C) 2020 ASRJS. This is an openaccess article distributed under the terms of the Creative Commons Attribution 4.0 International license.

Citation: George Younan, Maged Andrews, Umadevi Rangarajan, Danielle Eganhouse, Robert F. Ahmed, et al. Improved Pancreaticoduodenectomy Outcomes after Starting a Specialized Community Hospital Pancreatic Surgery Program. Med Clin Res Open Access. 2020;1(1):1-6. 


\section{Introduction}

Pancreatic surgery is one of the most complex disciplines among abdominal surgeries. Pancreaticoduodenectomy (PD) remains the golden standard procedure to treat diseases of the peri-ampullary area but continues to pose challenges even to experienced pancreatic surgeons due to its complexity. For a long time after its introduction, $\mathrm{PD}$ was associated with very high rates of morbidity reaching $60 \%$ and mortality reaching 20\% [1-3]. Improvement in outcomes resulted from emerging advances in technology and optimized perioperative management of complex surgeries. It has been shown that pancreatic surgery, specifically PD, has a volumeoutcome formula, where improved mortality and better outcomes were obtained in high volume centers when performed by high volume surgeons [4-7]. This correlation led to centralization or regionalization of pancreatic surgery to major tertiary care centers, further advocated for by the Leapfrog initiative [8-10]. It is still debatable as to whether hospital volume or surgeon volume or system processes are responsible for this effect $[11,12]$. In consequence, emerging reports from community hospitals demonstrated acceptable PD safety and outcomes [13,14].

A multispecialty surgical group in northern Virginia decided to expand into complex hepatopancreatobiliary surgery and hired a fellowship-trained pancreatic surgeon to partner with their fellowship-trained transplant and pancreatic surgeon. A specialty pancreatic surgery program was created and operated at two hospitals. One is a tertiary care hospital and the other, a sister community hospital both belonging to the same healthcare system. The aim of this study is to examine the outcomes of pancreatic surgery and specifically those of PD, for two high volume surgeons who improved their outcome after migrating their program to a community hospital.

\section{Methods}

Data was retrospectively collected from a prospectively-maintained database at the division of hepatopancreatobiliary surgery at Virginia Surgery Associates (Fairfax, VA). Medical records of patients who underwent pancreatic surgery with the two pancreatic surgery specialists of the group (GY and TRS), were identified and reviewed. Patients demographics, preoperative, intraoperative and postoperative parameters were analyzed. Data from August 2016 to December 2018 was collected, just after 60 consecutive PD were performed. We elected to stop at the $60 \mathrm{PD}$ limit as to adhere to the published learning curve threshold $[15,16]$. During this period, a total of 117 pancreatic surgeries were performed at two different institutions, a tertiary care center (TCC), and a community hospital $(\mathrm{CH})$, under the umbrella of the same healthcare system. Pancreatic procedures reviewed include PD, total pancreatectomy (TP), distal pancreatectomy and pancreatic drainage procedures. We only included $\mathrm{PD}(\mathrm{n}=60)$ and $\mathrm{TP},(\mathrm{n}=2)$, in our final analysis, for a total of 62 consecutive procedures.

The two surgeons started the program at the TCC, which has a large general surgery residency program, in August of 2016. Procedures there were done by one of the two surgeons assisted by a fifth-year general surgery resident. In April 2017, which is approximately eight months into the program, and based on the community requirements, both surgeons began performing these procedures at the $\mathrm{CH}$. One surgeon performed the procedure and the other surgeon acted as the assistant, residents were not part of the $\mathrm{CH}$ setting. By the end of 2017, all pancreatic surgeries were performed at the $\mathrm{CH}$ and this decision was mainly outcomes-driven.

All PD were done though an upper midline incision. The steps of the procedure were performed in the same way consistently. These steps have been published by Christians et. al. [17] The pancreatic reconstruction part of the procedure was done with end-to-side, duct-to-mucosa retrocolic pancreaticojejunostomy with interrupted absorbable sutures, and anterior and posterior layers following the modified Blumgart technique. The biliary anastomosis was done in an end-to-side fashion using interrupted absorbable sutures and the gastrojejunostomy was constructed in a two-layer, handsewn, antecolic, end-to-side fashion. We performed the standard PD procedure without sparing the pylorus. The postoperative care plan was standardized after a limited number of cases and an enhanced recovery post-PD recovery pathway was used. A multimodality pain pathway protocol was developed with the help of the anesthesia department at both hospitals. Patients were regularly admitted to monitored hepatobiliary unit surgical beds post-operatively with specially trained nursing staff and did not get admitted to the intensive care unit unless indicated.

Standard post-PD complications were measured using published guidelines from the International Study Group on Pancreatic Surgery and the Pancreas Club calculators [18-20]. Patient outcomes were compared using standard statistical methods, we compared outcomes of surgeries done at the TCC $(n=20)$, to the outcomes of surgeries done at the $\mathrm{CH}(n=40)$ after approval from the institutional review board as an outcomes study. Statistical analysis was done using GraphPad Prism (Lajolla, CA) and p-value $<0.05$ was considered significant.

\section{Results}

From August 2016 to December 2018, a total of 117 pancreatic surgeries were done at both hospitals. The pancreatic surgery program was initiated August of 2016 at the TCC. In April of 2017, the program expanded to the nearby $\mathrm{CH}$. The sixtieth $\mathrm{PD}$ was performed in December of 2018. The quarterly number of cases done initially picked up at both hospitals until August of 2017 where all procedures were done exclusively at the $\mathrm{CH}$ (Figure 1).

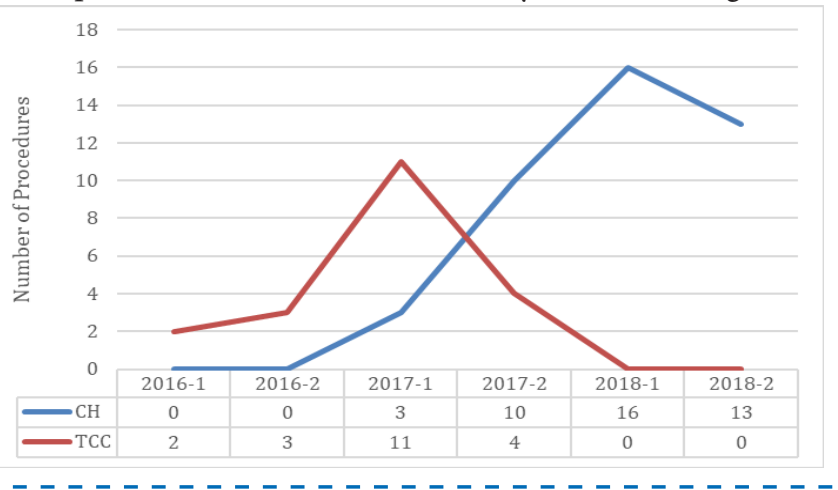

Pages 2 of 6 
Figure 1: Pancreaticoduodenectomy and total pancreatectomy procedures done at the Tertiary Care Center (TCC), and the Community Hospital (CH) between August of 2016 and December of 2018.

Patient demographics, indications for the procedures and the procedures performed are shown in Table 1. There was no significant difference between the two hospitals in regard to: patient median age ( 76 vs. 62 years), median body mass index ( 26.2 vs. $26 \mathrm{~kg} / \mathrm{m}^{2}$ ), gender ( 65 vs. $62 \%$ males), or American Society of Anesthesiologists (ASA) class. Additionally, indications and procedure types did not differ.

Table 1: Demographic and preoperative data.

\begin{tabular}{|c|c|c|c|c|}
\hline & & TTC & $\mathrm{CH}$ & p value \\
\hline Number & Procedures & 20 & 42 & \\
\hline Age $(\mathrm{M}$ & lian, Years) & 67 & 62 & 0.11 \\
\hline Mal & Gender & $13(65 \%)$ & $26(62 \%)$ & 0.52 \\
\hline $\mathrm{BM}$ & $\left.\mathrm{kg} / \mathrm{m}^{2}\right)$ & 26.2 & 26 & 0.89 \\
\hline & 1 & 0 & $1(2.4 \%)$ & \\
\hline$\triangle \mathrm{SA} C \mathrm{Cl}$ & 2 & $4(20 \%)$ & $6(14.3)$ & \\
\hline ASA CIASS & 3 & $14(70 \%)$ & $23(54.8 \%)$ & 0.54 \\
\hline & 4 & $2(10 \%)$ & $12(28.5 \%)$ & \\
\hline Type of & $\mathrm{PD}$ & $19(95 \%)$ & $41(97.6 \%)$ & 054 \\
\hline Procedure & $\mathrm{TP}$ & $1(5 \%)$ & $1(2.4 \%)$ & 0.54 \\
\hline & Malignancy & $15(75 \%)$ & $31(73.8 \%)$ & \\
\hline $\begin{array}{c}\text { Indication of } \\
\text { Procedure }\end{array}$ & Pre-malignancy & $2(10 \%)$ & $6(14.3 \%)$ & 0.58 \\
\hline & Pancreatitis & $3(15 \%)$ & $5(11.9 \%)$ & \\
\hline
\end{tabular}

Intraoperative variables and post-operative outcomes are shown in Table 2. Twenty patients were operated on at the TCC and fortytwo at the $\mathrm{CH}$. When procedures were performed at the $\mathrm{CH}$, there was a significant decrease in operative time of the procedure (350 and 281 minutes, $\mathrm{p}<0.01)$ and estimated blood loss (409 and 156 $\mathrm{ml}, \mathrm{p}<0.01)$. Intraoperative blood transfusions were reduced from $10 \%$ to zero, and post-operative transfusions from $10 \%$ to $2.4 \%$, however these results did not reach statistical significance. There was no difference in pancreatic duct diameter and pancreatic gland texture between patients. These features are known to increase the complexity of the reconstruction after PD and are known risk factors for post-operative pancreatic leaks [21].

Overall delayed gastric emptying was reduced from $20 \%$ to $4.8 \%$, Grade A from $15 \%$ to $2.4 \%$ and Grade B from $5 \%$ to $2.4 \%$. These results approached but did not reach statistical significance $(p=0.08)$. There was no Grade $\mathrm{C}$ delayed gastric emptying in this study. Pancreatic leak rates were similar between the two hospitals; there was one Grade B leak and one Grade Cleak at the TCC, versus two grade $\mathrm{B}$ and no Grade $\mathrm{C}$ leaks at the $\mathrm{CH}$. Intra-abdominal infections, which included any abscesses or fluid collections that needed to be treated with antibiotics or percutaneous drains and these included the pancreatic leaks, did not differ between the two hospitals, (10\% and $7.1 \%)$. Most patients were admitted to the regular hepatobiliary unit surgical beds, a small number of patients needed to be admitted to the intensive care unit, $15 \%$ at the TCC versus $7.1 \%$ at the $\mathrm{CH}$. Reasons for intensive care unit admission included the needs for continuous infusion drips that were not permitted on the surgical floor. Examples included insulin drips from total pancreatectomy patients and anti-arrhythmia cardiac drips for atrial fibrillation patients. Only one patient at the TCC needed the intensive care unit for hemodynamic instability requiring pressor support. Rates of deep vein thrombosis, pulmonary emboli were basically null. Only one patient at the $\mathrm{CH}$ had a post-operative urinary tract infection requiring antibiotics. Rates of R0 resection were high and similar between the two hospitals (90\% and 95.2\%). One of the main post-operative outcomes that reached clinical significance was the length of hospital stay and that was reduced from 7.2 to 5.2 days $(\mathrm{p}<0.01)$ for patients that had their surgery at the $\mathrm{CH}$. There was no statistical significance in terms of 30-day hospital readmissions between the two hospitals, however it was little increased at the $\mathrm{CH}(10 \%$ and $16.7 \%, \mathrm{p}=0.71)$.

There was only one reoperation and that one case was also the only 30-day mortality case in the whole study. Most of the cases were done for a malignancy diagnosis as evidenced by the final pathology of resected specimen (Table 3).

Table 2: Post-operative outcomes.

\begin{tabular}{|c|c|c|c|}
\hline & TTC, $n=20$ & $\mathrm{CH}, \mathrm{n}=42$ & $p$ value \\
\hline Operative Time (Min) & 350 & 281 & 0.0001 \\
\hline Estimated Blood Loss (ml) & 409 & 156 & 0.003 \\
\hline $\begin{array}{l}\text { Intraoperative Blood Trans- } \\
\text { fusion }\end{array}$ & $2(10 \%)$ & $0(0 \%)$ & 0.1 \\
\hline Nerve Block & $0(0 \%)$ & $42(100 \%)$ & 0.0001 \\
\hline PD Diameter (mm) & 3.6 & 3.5 & 0.91 \\
\hline Gland Texture (Soft \%) & $11(55 \%)$ & $22(52 \%)$ & 0.53 \\
\hline Delayed Gastric Emptying & & & 0.08 \\
\hline Grade A & $3(15 \%)$ & $1(2.4 \%)$ & \\
\hline Grade B & $1(5 \%)$ & $1(2.4 \%)$ & \\
\hline Grade C & $0(0 \%)$ & $0(0 \%)$ & \\
\hline $\begin{array}{l}\text { Post-operative Blood Trans- } \\
\text { fusion }\end{array}$ & $2(10 \%)$ & $1(2.4 \%)$ & 0.24 \\
\hline Pancreatic Leak & & & 0.58 \\
\hline Garde B & $1(5 \%)$ & $2(4.8 \%)$ & \\
\hline Grade C & $1(5 \%)$ & $0(0 \%)$ & \\
\hline Intra-abdominal Infection & $2(10 \%)$ & $3(7.1 \%)$ & 0.65 \\
\hline ICU Stay Requirement & $3(15 \%)$ & $3(7.1 \%)$ & 0.37 \\
\hline R0 Resection & $18(90 \%)$ & $40(95.2 \%)$ & 0.58 \\
\hline $\mathrm{DVT} / \mathrm{PE} / \mathrm{UTI}$ & $0(0 \%)$ & $1(2.4 \%)$ & 1 \\
\hline $\begin{array}{l}\text { Length of Hospital Stay } \\
\text { (Days) }\end{array}$ & 7.2 & 5.2 & 0.0001 \\
\hline 30-day Readmission & $2(10 \%)$ & $7(16.7 \%)$ & 0.71 \\
\hline Reoperation & $1(5 \%)$ & $0(0 \%)$ & 0.32 \\
\hline 30-day Mortality & $1(5 \%)$ & $0(0 \%)$ & 0.32 \\
\hline
\end{tabular}


Table 3: Pathology results.

\begin{tabular}{ccc}
\hline Diagnosis & No. of Cases & Percentage \\
Malignant Pathology & 46 & 74.2 \\
PDAC & 33 & 53.2 \\
PNET & 6 & 9.7 \\
AAC & 2 & 3.2 \\
DAC & 3 & 4.8 \\
CCA & 1 & 1.6 \\
GCA & 1 & 1.6 \\
Premalignant Pathology & 7 & 11.3 \\
IPMN & 7 & 11.3 \\
Benign Pathology & 9 & 14.5 \\
Pancreatitis & 8 & 12.9 \\
Adenoma & 1 & 1.6 \\
\hline
\end{tabular}

\section{Discussion}

Pancreatic surgery outcomes have been widely studied; definitions and guidelines have been nationally and internationally published $[1,18,19,22,23]$. It has become evident that volume-quality relationship applies to complex abdominal surgeries. High-volume centers and high-volume surgeons obtain better overall outcomes after PD [5,6,10,24-26]. These trends advocated for centralization of complex abdominal surgeries to high-volume tertiary care centers, nationally and internationally [25,27-30]. Several obstacles to centralization were met during this process, which were country and state-specific. In general, these were related to the following: feasibility of access to cancer care, disparity between patient groups, commercial insurance variability and changing government health policies $[9,31]$.

In the face of centralization concerns, multiple community hospitals and surgeons at smaller institutions started publishing their results, showing comparable feasibility and safety in undergoing complex surgeries [11,13,32,33]. An ongoing debate exists now as to the nature of the defining denominators of superior outcomes in highvolume institutions [34]. A gray area exists when high-volume surgeons operate at low-volume hospitals, or low-volume surgeons operate at high-volume hospitals [35]. Surgeon experience remains the backbone on which pancreatic surgery programs rely $[12,36]$. There is a growing but stable trend in achieving acceptable and comparable outcomes in community hospitals adopting pancreatic surgery. This is largely due to high-volume experienced surgeons migrating to community hospitals, and thus altering these institutions' status into high-volume hospitals [11,13,32,37].

Virginia Surgery Associates is a private general surgery group in Northern Virginia. The group has been serving the community since 1978. In the last decade, the group made the decision to expand into surgical subspecialties in its covered area. Consequently, the hepatopancreatobiliary subdivision was created when they recruited a fellowship-trained pancreatic surgeon (GY) to partner with their fellowship-trained transplant surgeon. Procedures were initially performed at the high-volume TCC that is the base for a large general surgery residency program, where pancreatic surgeons served as teaching faculty. Community needs and referral trends allowed the group and its pancreatic surgeons to extend the pancreatic surgery program to a smaller sister community institution. Outcomes at the $\mathrm{CH}$ program eventually led to the full migration of the program to that institution. In less than two years, the program became a high-volume program and met all national benchmarks in pancreatic surgery [38]. The program outcomes were feasible, reproducible, safe and comparable to outcomes from major institutions $[1,7,27]$. At this early point in the program, the team was able to decrease operative time, operative blood loss, and length of hospital stay in a significant fashion. Although other outcomes results did not reach statistical significance, they did reach clinical significance. These include the overall decrease in rates of pancreatic leaks, which is "the Achilles heel" of the PD procedure. In addition to the overall decrease in: delayed gastric emptying, intra-abdominal infections, and ICU stay, there was a noteworthy improved rate of R0 resections reaching an excellent $95 \%$ in the $\mathrm{CH}$ setting.

These noteworthy improvements cannot be solely attributed to surgeon volume. Initiating the program at the $\mathrm{CH}$ was implemented only after a detailed and thorough plan was constructed in conjunction with the administration of the $\mathrm{CH}$. Previously, the $\mathrm{CH}$ had in place its established cancer center as well as its own tumor boards and multidisciplinary teams. Furthermore, twenty-fourhour interventional radiology and interventional gastroenterology coverage was already in place, and the requirements for experienced cytological and pathological care were met. In fact, the pathology departments in both hospitals are administered by the same group.

Intraoperatively, the program was assigned a dedicated consistent team of specialty anesthesiologists and operating room personnel. An enhanced recovery pathway was used by the anesthesia team to reduce intraoperative volume and narcotic use. A multimodality pain pathway was implemented, this was started with a peripheral nerve block performed immediately after induction, again, performed by the same consistent anesthesia team.

A post-operative enhanced recovery pathway was also used on the surgical floor. This followed published international guidelines with some modifications that will be separately published by our group [39]. The planned hospital stay after a PD was reduced to 5 days and was accomplished in the majority of cases at the $\mathrm{CH}$. All patients were discharged home on a full liquid diet and diets were advanced on an outpatient basis.

In addition, post discharge care provided was also highly advanced and detailed. The group's nurse navigator performed daily post discharge care via phone calls and a weekly follow up office visit. The group's pancreatic surgeons were available around the clock for direct communication with patients. The pancreatic surgeons were also available for patient hospital rounding on daily basis, including weekends. 
This study has many limitations due its nature. It is meant to publish the improved outcomes of a new pancreatic surgery program in the Northern Virginia community area. Limitations include small patient numbers, different characteristics of both hospitals, the retrospective nature of the study, even though the patient database was prospectively maintained. The strict adherence to the enhanced recovery pathway was mainly applied at the $\mathrm{CH}$ and was not very strictly followed at the TCC, as it was first introduced at that hospital, and it needed TCC staff and residents some time to apply it. One bias is the use of peripheral nerve blocks (PNB) with long-acting liposomal agents at the $\mathrm{CH}$, the procedure was not used at the TCC. There are mixed reviews whether or not nerve blocks help, we believe they do in our cohort and may have partly contributed to better short-term surgical outcomes. Procedures were performed by a surgeon and a senior resident at the TCC. Both surgeons assisted each other performing these cases at the $\mathrm{CH}$ without the use of trainees or surgical assistants. A high degree of standardization was achieved once the program relocated to the $\mathrm{CH}$.

Regionalization of complex procedures allows improved outcomes if patients can travel to high-volume institutions. However, high-volume surgeons are taking advantage of the widespread dissemination of healthcare and building high-volume programs in the community. As evidenced by the results in this study; with dedicated institutional support and careful program design, complex procedures such as PD can be successfully relocated to the community where superior results can be achieved.

\section{References}

1. Cameron JL, He J. Two thousand consecutive pancreaticoduodenectomies. J Am Coll Surg. 2015;220(4):530536.

2. Yeo CJ, Cameron JL, Sohn TA, et al. Six hundred fifty consecutive pancreaticoduodenectomies in the 1990s: pathology, complications, and outcomes. Ann Surg. 1997;226(3):248-257; discussion 257-260.

3. Piorkowski RJ, Blievernicht SW, Lawrence W, Jr., et al. Pancreatic and periampullary carcinoma. Experience with 200 patients over a 12 year period. Am J Surg. 1982;143(2):189193.

4. Begg CB, Cramer LD, Hoskins WJ, Brennan MF. Impact of hospital volume on operative mortality for major cancer surgery. JAMA. 1998;280(20):1747-1751.

5. Birkmeyer JD, Siewers AE, Finlayson EV, et al. Hospital volume and surgical mortality in the United States. N Engl J Med. 2002;346(15):1128-1137.

6. Birkmeyer JD, Stukel TA, Siewers AE, Goodney PP, Wennberg DE, Lucas FL. Surgeon volume and operative mortality in the United States. N Engl J Med. 2003;349(22):2117-2127.

7. McPhee JT, Hill JS, Whalen GF, et al. Perioperative mortality for pancreatectomy: a national perspective. Ann Surg. 2007;246(2):246-253.

8. Stitzenberg KB, Meropol NJ. Trends in centralization of cancer surgery. Ann Surg Oncol. 2010;17(11):2824-2831.
9. Stitzenberg KB, Sigurdson ER, Egleston BL, Starkey RB, Meropol NJ. Centralization of cancer surgery: implications for patient access to optimal care. J Clin Oncol. 2009;27(28):46714678.

10. Finks JF, Osborne NH, Birkmeyer JD. Trends in hospital volume and operative mortality for high-risk surgery. $\mathrm{N} \mathrm{Engl} \mathrm{J}$ Med. 2011;364(22):2128-2137.

11. Toomey PG, Teta AF, Patel KD, Ross SB, Rosemurgy AS. Highvolume surgeons vs high-volume hospitals: are best outcomes more due to who or where? Am J Surg. 2016;211(1):59-63.

12. Wood TW, Ross SB, Bowman TA, et al. High-Volume Hospitals with High-Volume and Low-Volume Surgeons: Is There a "Field Effect" for Pancreaticoduodenectomy? Am Surg. 2016;82(5):407-411.

13. Hardacre JM, Raigani S, Dumot J. Starting a High-Quality Pancreatic Surgery Program at a Community Hospital. J Gastrointest Surg. 2015;19(12):2178-2182.

14. Riediger H, Adam U, Utzolino S, Neeff HP, Hopt UT, Makowiec F. Perioperative outcome after pancreatic head resection: a 10year series of a specialized surgeon in a university hospital and a community hospital. J Gastrointest Surg. 2014;18(8):14341440.

15. Tseng JF, Pisters PW, Lee JE, et al. The learning curve in pancreatic surgery. Surgery. 2007;141(5):694-701.

16. Hardacre JM. Is there a learning curve for pancreaticoduodenectomy after fellowship training? HPB Surg. 2010;2010:230287.

17. Christians KK, Tsai S, Tolat PP, Evans DB. Critical steps for pancreaticoduodenectomy in the setting of pancreatic adenocarcinoma. J Surg Oncol. 2013;107(1):33-38.

18. Bassi C, Marchegiani G, Dervenis C, et al. The 2016 update of the International Study Group (ISGPS) definition and grading of postoperative pancreatic fistula: 11 Years After. Surgery. 2017;161(3):584-591.

19. Wente MN, Veit JA, Bassi C, et al. Postpancreatectomy hemorrhage (PPH): an International Study Group of Pancreatic Surgery (ISGPS) definition. Surgery. 2007;142(1):20-25.

20. Malleo G, Crippa S, Butturini G, et al. Delayed gastric emptying after pylorus-preserving pancreaticoduodenectomy: validation of International Study Group of Pancreatic Surgery classification and analysis of risk factors. HPB (Oxford). 2010;12(9):610-618.

21. Callery MP, Pratt WB, Kent TS, Chaikof EL, Vollmer CM, Jr. A prospectively validated clinical risk score accurately predicts pancreatic fistula after pancreatoduodenectomy. J Am Coll Surg. 2013;216(1):1-14.

22. Ball CG, Dixon E, Vollmer CM, Howard TJ. The view from 10,000 procedures: technical tips and wisdom from master pancreatic surgeons to avoid hemorrhage during pancreaticoduodenectomy. BMC Surg. 2015;15:122.

23. Pugalenthi A, Protic M, Gonen $M$, et al. Postoperative complications and overall survival after pancreaticoduodenectomy for pancreatic ductal adenocarcinoma. J Surg Oncol. 2016;113(2):188-193.

24. Lieberman MD, Kilburn H, Lindsey M, Brennan MF. Relation 
of perioperative deaths to hospital volume among patients undergoing pancreatic resection for malignancy. Ann Surg. 1995;222(5):638-645.

25. Fong Y, Gonen M, Rubin D, Radzyner M, Brennan MF. Longterm survival is superior after resection for cancer in highvolume centers. Ann Surg. 2005;242(4):540-544; discussion 544-547.

26. de Wilde RF, Besselink MG, van der Tweel I, et al. Impact of nationwide centralization of pancreaticoduodenectomy on hospital mortality. Br J Surg. 2012;99(3):404-410.

27. van der Geest LG, van Rijssen LB, Molenaar IQ, et al. Volumeoutcome relationships in pancreatoduodenectomy for cancer. HPB (Oxford). 2016;18(4):317-324.

28. Swan RZ, Niemeyer DJ, Seshadri RM, et al. The impact of regionalization of pancreaticoduodenectomy for pancreatic Cancer in North Carolina since 2004. Am Surg. 2014;80(6):561566.

29. Sonnenday CJ, Birkmeyer JD. A tale of two provinces: regionalization of pancreatic surgery in Ontario and Quebec. Ann Surg Oncol. 2010;17(10):2535-2536.

30. Gordon TA, Bowman HM, Tielsch JM, Bass EB, Burleyson GP, Cameron JL. Statewide regionalization of pancreaticoduodenectomy and its effect on in-hospital mortality. Ann Surg. 1998;228(1):71-78.

31. Murphy MM, Simons JP, Ng SC, et al. Racial differences in cancer specialist consultation, treatment, and outcomes for locoregional pancreatic adenocarcinoma. Ann Surg Oncol. 2009;16(11):2968-2977.

32. Ansari D, Williamsson C, Tingstedt B, Andersson B, Lindell
G, Andersson R. Pancreaticoduodenectomy--the transition from a low- to a high-volume center. Scand J Gastroenterol. 2014;49(4):481-484.

33. Khithani A, Christian D, Lowe $\mathrm{K}$, et al. Feasibility of pancreaticoduodenectomy in a nonuniversity tertiary care center: what are the key elements of success? Am Surg. 2011;77(5):545-551.

34. Chau Z, West JK, Zhou Z, et al. Rankings versus reality in pancreatic cancer surgery: a real-world comparison. HPB (Oxford). 2014;16(6):528-533.

35. Enomoto LM, Gusani NJ, Dillon PW, Hollenbeak CS. Impact of surgeon and hospital volume on mortality, length of stay, and cost of pancreaticoduodenectomy. J Gastrointest Surg. 2014;18(4):690-700.

36. Schmidt CM, Turrini O, Parikh P, et al. Effect of hospital volume, surgeon experience, and surgeon volume on patient outcomes after pancreaticoduodenectomy: a single-institution experience. Arch Surg. 2010;145(7):634-640.

37. Shah OJ, Singh M, Lattoo MR, Bangri SA. Pancreaticoduodenectomy: A study from India on the impact of evolution from a low to a high volume unit. World J Gastrointest Surg. 2016;8(8):583-589.

38. Traverso LW, ShinchiH,Low DE. Useful benchmarks to evaluate outcomes after esophagectomy and pancreaticoduodenectomy. Am J Surg. 2004;187(5):604-608.

39. Lassen K, Coolsen MM, Slim K, et al. Guidelines for perioperative care for pancreaticoduodenectomy: Enhanced Recovery After Surgery (ERAS(R)) Society recommendations. World J Surg. 2013;37(2):240-258. 